\title{
Listeria monocytogenes meningitis in immunocompetent and healthy children: a case report and a review of the literature
}

\author{
Massimo Luca Castellazzi, Paola Marchisio and Samantha Bosis*
}

\begin{abstract}
Background: Listeria monocytogenes is a gram-positive bacteria generally transmitted to humans through ingestion of contaminated food. It typically infects high risk subjects, such as pregnant women, neonates, the elderly and immunocompromised patients. Listeria meningitis is rarely reported in previously healthy children with no immunological disorders. However, it can be aggressive in such subjects and is associated with a high mortality rate. Prompt diagnosis is essential so that adequate antibiotic treatment can be started and the best outcome achieved.

Case presentation: We report the case of a previously healthy 16-month-old child with Listeria meningitis who was successfully treated with intravenous ampicillin and gentamicin without any sequelae.

Conclusions: Although Listeria meningitis is rare in previously healthy immunocompetent children, it must be considered, especially in children who do not improve with first-line antibiotic treatment. A review of the literature published since 1996 has been performed, to provide a general overview on this topic.
\end{abstract}

Keywords: Listeria monocytogenes, Meningitis, Immunocompetent child

\section{Background}

Listeria (L.) monocytogenes is a gram-positive facultative intracellular bacteria transmitted to humans through ingestion of contaminated food, in particular ready-to-eat food, products with a long shelf life, deli meats and soft cheeses. It typically affects pregnant women, neonates, the elderly and immunocompromised patients [1]. An infection during pregnancy can cause abortion, premature birth and amniositis, whereas in neonates it can cause late-onset meningitis, conjunctivitis and pneumonia. In immunocompromised patients Listeria causes central nervous system infection, endocarditis, and sepsis [2]. There are rare reports of Listeria meningitis in previously healthy and immunocompetent children, which may be associated with severe complications and a high mortality rate [2].

The clinical symptoms of Listeria meningitis are similar to those of other causes of meningoencephalitis and first-line treatment with third-generation cephalosporins

\footnotetext{
*Correspondence: samantha.bosis@policlinico.mi.it

Pediatric Highly Intensive Care Unit, Department of Pathophysiology and

Transplantation, Università degli Studi di Milano, Fondazione IRCCS Ca'

Granda Ospedale Maggiore Policlinico, Milan, Italy
}

is ineffective. Awareness of this pathogen is therefore crucial, to enable adequate treatment to be started and the best outcome to be achieved.

We report on a case of Listeria meningitis in a previously healthy 16-month-old girl. We also review literature reports of this condition in post-neonatal immunocompetent children, published in English since 1996, in order to discuss its clinical presentation, diagnosis, treatment options and prognosis.

\section{Case presentation}

A previously healthy, fully immunized, 16-month-old girl was hospitalized for high grade fever (maximum axillary temperature of $39.8^{\circ} \mathrm{C}$ ), vomiting and refusal to feed of 4 days' duration and irritability of recent onset. She had been receiving oral antibiotic treatment with amoxicillinclavulanic acid $(50 \mathrm{mg} / \mathrm{kg} /$ day every $8 \mathrm{~h}$ ) for $24 \mathrm{~h}$, without any clinical improvement. On admission (day 1 ) the patient was irritable but in good general condition. Physical findings were as follows: body weight $11 \mathrm{~kg}$; heart rate 101 beats/min; body temperature $38^{\circ} \mathrm{C}$; oxygen saturation in room air 98\%; blood pressure 90/50 $\mathrm{mmHg}$. The cardiorespiratory and abdominal examinations were normal and no

(c) The Author(s). 2018 Open Access This article is distributed under the terms of the Creative Commons Attribution 4.0 International License (http://creativecommons.org/licenses/by/4.0/), which permits unrestricted use, distribution, and reproduction in any medium, provided you give appropriate credit to the original author(s) and the source, provide a link to the Creative Commons license, and indicate if changes were made. The Creative Commons Public Domain Dedication waiver (http://creativecommons.org/publicdomain/zero/1.0/) applies to the data made available in this article, unless otherwise stated. 
skin rash was observed. There was no sign of meningitis. Laboratory tests showed elevated white blood cell (WBC) counts of $14,090 / \mathrm{mmc}$ ( $75.7 \%$ neutrophils), while the C-reactive protein (CRP) concentration was $5.76 \mathrm{mg} / \mathrm{dl}$ (normal value $<0.5 \mathrm{mg} / \mathrm{dl}$ ). Electrolytes, renal function and coagulation tests were within the normal range. Given her vomiting, the ongoing oral antibiotic treatment was stopped and intravenous ceftriaxone $(100 \mathrm{mg} / \mathrm{kg} /$ day in a single dose) was started in the suspicion of a bacterial infection.

On day 2 the patient rapidly worsened. She was lethargic and preferred the lying position. Neck stiffness and Brudzinski's sign were also noted. A computed tomography scan of the brain was normal, with no signs of increased intracranial pressure. A lumbar puncture was performed, revealing clear cerebrospinal fluid (CSF) containing 840 cells $/ \mathrm{mmc}$ with neutrophilic predominance and glucose and protein concentrations of 38 and $44 \mathrm{mg} /$ dl respectively. Empiric parenteral antibiotic treatment with ceftriaxone $(100 \mathrm{mg} / \mathrm{kg} /$ day $)$ was continued and intravenous antiviral therapy with acyclovir $(30 \mathrm{mg} / \mathrm{kg} /$ day in 3 doses) was started. Gram-staining resulted negative.

On day 3, a real-time polymerase chain reaction (RT-PCR) for viruses and bacteria was positive for $L$. monocytogenes. Ceftriaxone was therefore discontinued and intravenous ampicillin $(200 \mathrm{mg} / \mathrm{kg} /$ day in 4 doses $)$ and gentamicin $(5 \mathrm{mg} / \mathrm{kg} /$ day $)$ were started.

On day 4, the CSF culture identified L. monocytogenes, while the blood culture was negative. A brain magnetic resonance imaging scan showed mild meningeal enhancement without any sign of parenchymal involvement.

The patient improved rapidly after the initiation of ampicillin and gentamicin. She was completely afebrile from day 7 and was progressively alert and communicative by day 10. Ampicillin and gentamicin were continued for a total of 21 days, while acyclovir was continued until the RT-PCR for Herpes simplex viruses proved negative. The patient was discharged after 22 days in good general condition and without any neurologic sequelae. Immunological screening, including an evaluation of cellular immunity (total and subpopulations of $\mathrm{T}$ cells), humoral immunity (immunoglobulin levels and subclass IgG) and complement (C3, C4, AP50, CH50), was normal. An HIV test was negative and there was no iron overload. A hearing test (auditory evoked potentials) was normal. At a follow-up visit after 1 month, her clinical presentation was normal and there were no signs of the disease. No source of infection was clarified in her recent history.

\section{Discussion and conclusion}

L. monocytogenes meningoencephalitis in previously healthy immunocompetent children is rare, but it can progress rapidly and may be associated with severe complications, such as acute hydrocephalus, and a high mortality rate [3]. Early diagnosis and adequate treatment are therefore essential to achieve the best outcome. Unfortunately, adequate therapy might be delayed, and it is essential that Listeria meningitis is considered in cases that do not improve following first-line treatment with extended-spectrum cephalosporins for central nervous system infections.

To discuss the clinical presentation, diagnosis, treatment and prognosis of this disease, we performed a literature review of Listeria meningitis in previously healthy children without any immunological disorders, in order to help pediatricians promptly recognize and treat it. We identified 16 case reports involving 21 patients with Listeria meningitis published in English since 1996. Most of these cases shows similarities with our own case report.

The clinical presentation of Listeria meningitis is non-specific and similar to that seen with other types of viral or bacterial meningitis. The signs and symptoms include fever, headache, vomiting, diarrhea and altered mental status [1-16], as also seen in our case. Abducens nerve palsy and nystagmus have also been reported among the initial signs of clinical presentation in some cases $[8,10,12,13]$. Listeria meningitis was preceded by rotavirus gastroenteritis and by meningococcal $\mathrm{B}$ meningitis in two cases $[13,14]$. The age at presentation varied from 7 months to 10 years. Most children, including our patient, presented with leukocytosis with neutrophilia and with elevated CRP. Lumbar puncture is essential for diagnosis, as blood cultures are often negative: only 5 cases had a blood culture positive for $L$. monocytogenes $[2,3,5,8,12]$. CSF analysis reveals in most cases pleocytosis with neutrophilia, reduced glucose concentration and increased protein levels.

Gram-staining is of limited use as it is negative in most cases. However, positivity for bacillus bacteria should not be automatically considered as a contaminant. In our case, gram-staining was negative, but RT-PCR was rapidly positive for L. monocytogenes, confirming the utility of this technique in identifying this pathogen and in guiding adequate antibiotic therapy [17, 18]. Initial CSF gram-staining and culture were reported as negative in a few cases at the first lumbar puncture $[2,3,6]$. Repetition of the CSF analysis is therefore advised in cases of severe meningoencephalitis that do not improve with first-line antibiotic treatment where no specific organism was identified on initial evaluation [2].

Finally, in one case diagnosis was based on serologic tests [9]. However, serologic testing for Listeria meningitis lacks specificity and should only be used for retrospective diagnosis [15].

First-line empiric treatment of meningitis frequently includes third-generation cephalosporins and vancomycin to target the most common pathogens [19]. However, once $L$. monocytogenes has been isolated from the CSF, the 


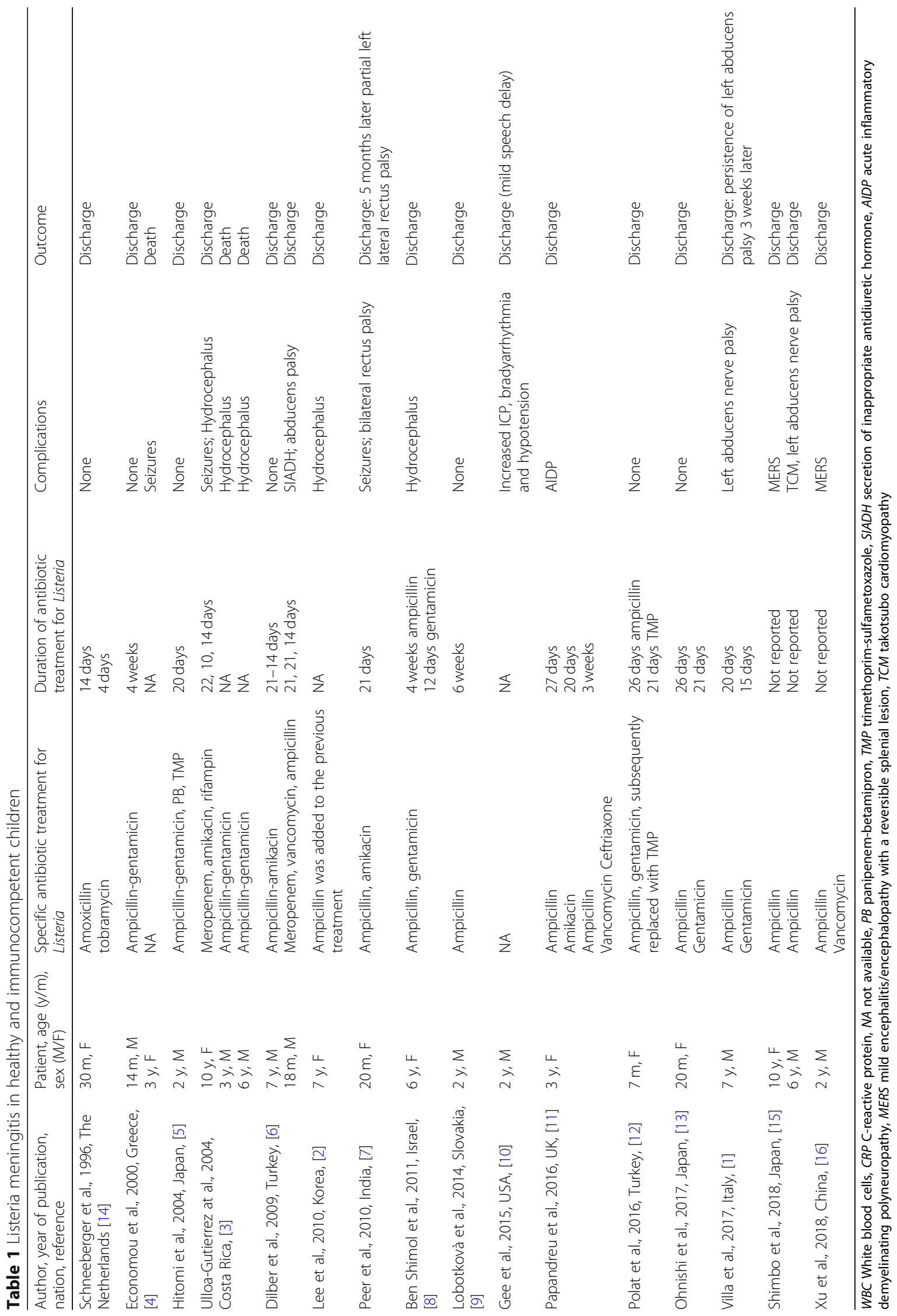


treatment should be adjusted to include ampicillin alone or in combination with an aminoglycoside, such as gentamicin or amikacin. Only one in-vitro study has demonstrated that this association is synergic [20]. Although vancomycin may be effective against $L$. monocytogenes on in-vitro testing, it has had a high failure rate clinically [2]. Furthermore, its penetration in CSF is poor [21].

Trimethoprim-sulfamethoxazole was recently described as an effective alternative in CNS listeriosis refractory to conventional treatment [12]. Carbapenems, used alone or in combination with aminoglycoside, have also produced good results $[3,5,6]$. The treatment duration varied from 10 days to a maximum of 8 weeks, depending on the severity of the case. In our case, 21 days of ampicillin and gentamicin were sufficient and the patient was discharged without any sequelae. Table 1 summarizes the main characteristics of Listeria meningitis in healthy and immunocompetent children.

As $L$. monocytogenes mainly affects immunocompromised hosts, an immunological evaluation could be useful. Underlying causes of immunosuppression, such as prolonged or inappropriate corticosteroid treatment, should be excluded [9]. Finally, blood iron levels should be checked, as iron overload could predispose to Listeria meningitis [22].

L. monocytogenes is a rare cause of meningoencephalitis in previously healthy, immunocompetent children. However, its clinical presentation is similar to that of other viral or bacterial CNS infections and its course can be rapid and aggressive. Physicians should therefore always consider $L$. monocytogenes as a possible etiologic agent of meningoencephalitis, especially in cases that are unresponsive to the empiric first-line antibiotic treatment and when gram-positive bacilli are observed in the CSF. Furthermore, real-time PCR, as in our case, may be useful for prompt diagnosis, which is essential to enable adequate antibiotic treatment to be started with ampicillin alone or in combination with aminoglycoside.

\section{Abbreviations}

CRP: C-reactive protein; CSF: Cerebrospinal fluid; L: Listeria; RT-PCR: Real-time polymerase chain reaction; WBC: White blood cell count

\section{Funding}

Nothing to declare.

\section{Availability of data and materials}

Data sharing not applicable to this case report because no datasets were generated or analyzed during the current study.

\section{Authors' contributions}

MLC and SB wrote the first draft of the manuscript and contributed to the patient management. PM critically revised the manuscript and supervised the patient management. All the author read and approved the final version of the manuscript.

\section{Ethics approval and consent to participate}

This case report was approved by the Ethics Committee of Fondazione IRCCS Ca' Granda Ospedale Maggiore Policlinico, Milan, Italy. For case reports, the Ethics Committee of Fondazione IRCCS Ca' Granda Ospedale Maggiore Policlinico does not provide a reference number.

\section{Consent for publication}

Written informed consent for the publication of this case report was obtained from the patient's parents. A copy of the written consent is available for review by the Editor-in-Chief of this journal.

\section{Competing interests}

The authors declare that they have no competing interests.

\section{Publisher's Note}

Springer Nature remains neutral with regard to jurisdictional claims in published maps and institutional affiliations.

Received: 4 October 2018 Accepted: 10 December 2018

Published online: 29 December 2018

\section{References}

1. Villa G, Diana MC, Solari N, Bandettini R, Sorrentino S, Loy A, Losurdo G, Renna S. Listeria meningitis in an immunocompetent child. Pediatr Emerg Care. 2017. https://doi.org/10.1097/PEC.0000000000000687.

2. Lee JE, Cho WK, Nam CH, Jung MH, Kang JH, Suh BK. A case of meningoencephalitis caused by Listeria monocytogenes in a healthy child. Korean J Pediatr. 2010. https://doi.org/10.3345/kjp.2010.53.5.653.

3. Ulloa-Gutierrez R, Avila-Agüero ML, Huertas E. Fulminant Listeria monocytogenes meningitis complicated with acute hydrocephalus in healthy children beyond the newborn period. Pediatr Emerg Care. 2004. https://doi.org/10.1097/01.pec.0000121243.99242.a9.

4. Economou M, Karyda S, Kansouzidou A, Kavaliotis J. Listeria meningitis in children: report of two cases. Infection. 2000;28:121-3.

5. Hitomi S, Ohto T, Okamoto M, Nishimura Y, Iwasaki N, Matsui A. A case of listerial meningitis treated with a regimen containing panipenembetamipron. J Infect Chemother. 2004. https://doi.org/10.1007/s10156-0040323-5.

6. Dilber E, Aksoy A, Cakir M, Bahat E, Kamaşak T, Dilber B. Listeria monocytogenes meningitis in two immunocompetent children. Ann Trop Paediatr. 2009. https://doi.org/10.1179/027249309X12467994694058.

7. Peer MA, Nasir RA, Kakru DK, Fomda BA, Wani MA, Hakeem QN. Listeria monocytogenes meningoencephalitis in an immunocompetent, previously healthy 20-month old female child. Indian J Med Microbiol. 2010. https:// doi.org/10.4103/0255-0857.62500.

8. Ben Shimol S, Einhorn M, Greenberg D. Listeria meningitis and ventriculitis in an immunocompetent child: case report and literature review. Infection. 2012. https://doi.org/10.1007/s15010-011-0177-6.

9. Lobotková D, Dická E, Rolný V, Stankovič I, Čižnár P. Systemic Listeria monocytogenes infection in a 2-year-old immunocompetent child. Infection. 2014. https://doi.org/10.1007/s15010-014-0655-8.

10. Gee SW, Karsies TJ. Listeria meningitis-associated bradyarrhythmia treated with isoproterenol. Am J Emerg Med. 2015. https://doi.org/10.1016/j.ajem. 2014.06.022

11. Papandreou A, Hedrera-Fernandez A, Kaliakatsos M, Chong WK, Bhate S. An unusual presentation of paediatric Listeria meningitis with selective spinal grey matter involvement and acute demyelinating polyneuropathy. Eur J Paediatr Neurol. 2016. https://doi.org/10.1016/j.ejpn.2015.08.004.

12. Polat M, Kara SS, Tapısız A, Derinöz O, Çağlar K, Tezer H. Successful treatment of refractory listeria meningitis and bacteremia with trimethoprim-sulfamethoxazole in an immunocompetent child. Turk J Pediatr. 2016. https://doi.org/10.24953/turkjped.2016.02.017.

13. Ohnishi T, Kawano A, Araki M, Hamahata Y, Usui M, Shimoyamada M, Tamame T, Akashi M, Sato S. Listeria monocytogenes meningitis complicating rotavirus gastroenteritis in an immunocompetent child. Keio J Med. 2017. https://doi.org/10.2302/kjm.2016-0007-CR.

14. Schneeberger $P$, Sluiter $E$, van Doorn LJ, Spanjaard L. Listeria meningitis during treatment of a meningococcal meningitis in an immunocompetent infant. Scand J Infect Dis. 1996.

15. Shimbo A, Takasawa K, Nishioka M, Morio T, Shimohira M. Complications of Listeria meningitis in two immunocompetent children. Pediatr Int. 2018; 60(5):491-2. https://doi.org/10.1111/ped.13550.

16. Xu J, Gao F, Yuan Z, Jiang L, Xia Z, Zhao Z. Mild encephalitis/ encephalopathy with a reversible splenial lesion (MERS) associated with 
bacteria meningitis caused by listeria monocytogenes: a case report. Medicine (Baltimore). 2018. https://doi.org/10.1097/MD.0000000000011561.

17. Le Monnier A, Abachin E, Beretti JL, Berche P, Kayal S. Diagnosis of Listeria monocytogenes meningoencephalitis by real-time PCR for the hly gene. J Clin Microbiol. 2011. https://doi.org/10.1128/JCM.01072-11.

18. Chiba N, Murayama SY, Morozumi M, Nakayama E, Okada T, Iwata S, Sunakawa K, Ubukata K. Rapid detection of eight causative pathogens for the diagnosis of bacterial meningitis by real-time PCR. J Infect Chemother. 2009. https://doi.org/10.1007/s10156-009-0670-3.

19. Tunkel AR, Hartman BJ, Kaplan SL, Kaufman BA, Roos KL, Scheld WM, Whitley RJ. Practice guidelines for the management of bacterial meningitis. Clin Infect Dis. 2004. https://doi.org/10.1086/425368.

20. Azimi PH, Koranyi K, Lindsey KD. Listeria monocytogens: synergistic effects of ampicillin and gentamicin. Am J Clin Pathol. 1979.

21. Weston VC, Punt J, Vloebeghs M, Watson AR, Ispahani P. Listeria monocytogenes meningitis in a penicillin-allergic paediatric renal transplant patient. J Inf Secur. 1998;37(1):77-8.

22. Mossey RT, Sondheimer J. Listeriosis in patients with long-term hemodialysis and transfusional iron overload. Am J Med. 1985

Ready to submit your research? Choose BMC and benefit from:

- fast, convenient online submission

- thorough peer review by experienced researchers in your field

- rapid publication on acceptance

- support for research data, including large and complex data types

- gold Open Access which fosters wider collaboration and increased citations

- maximum visibility for your research: over $100 \mathrm{M}$ website views per year

At $\mathrm{BMC}$, research is always in progress.

Learn more biomedcentral.com/submissions 